Pacific

Journal of

Mathematics

\title{
CORRECTION TO: \\ EGGERT'S CONJECTURE ON THE DIMENSIONS \\ OF NILPOTENT ALGEBRAS
}

LAKHDAR HAMMOUDI 


\title{
CORRECTION TO: EGGERT'S CONJECTURE ON THE DIMENSIONS OF NILPOTENT ALGEBRAS
}

\author{
LAKHDAR HAMMOUDI
}

Volume 202:1 (2002), 93-97

The author acknowledges that the Theorem in the paper in question does not solve Eggert's conjecture completely, because it uses the fact that $R \cap(A \oplus \mathbb{K})=\{0\}$. Indeed, in the proof of the Theorem (page 96, lines 19 to 24), we assume that the unions in lines 17 and 18 are disjoint. If we add this hypothesis to the Theorem, which is fulfilled by graded algebras for example, the result is correct.

Therefore, the proof of the Theorem yields only a particular case of Eggert's conjecture. Eggert's conjecture in general remains open.

The author thanks Professors B. Amberg and L. Kazarin for pointing out the mistake and for the valuable discussions.

Received September 9, 2004.

LAKHDAR HAMMOUDI

DEPARTMENT OF MATHEMATICS

OHIO UNIVERSITY-CHILLICOTHE

101 UNIVERSITY DRIVE

Chillicothe, OH 45601

UNITED STATES

hammoudi@ohio.edu 